\title{
Hacia una concepción más técnica y moderna de los cuerpos de funcionarios: el cuerpo como correlato de las áreas funcionales
}

\author{
Josefa Cantero Martínez*
}

Recibido: 16/11/2016 / Aceptado: 14/02/2017

Resumen. Nos proponemos en este trabajo hacer una reflexión sobre la necesidad de modernizar la concepción clásica del cuerpo de funcionarios. El cuerpo, entendido como una agrupación de funcionarios, ha sido el elemento más representativo de nuestro modelo de función pública. Sin embargo, hace ya más de sesenta años que se introdujo un nuevo elemento en la estructura funcionarial, el puesto de trabajo, entendido como el conjunto de funciones y tareas que se atribuyen a una persona. Desde entonces, ambas instituciones deben convivir en la Administración como elementos necesarios y no alternativos. A partir de ahí, nos proponemos actualizar la noción del cuerpo funcionarial para hacerla más compatible y acorde con la nueva estructura dual de la función pública. El cuerpo podría ser concebido como un correlato de las agrupaciones de puestos previamente identificadas por la Administración.

Palabras clave: cuerpos de funcionarios, puestos de trabajo, agrupaciones de puestos, áreas funcionales, y estructura funcionarial.

\section{Towards a more technical and modern conception of the bodies of official: The body as a correlate of the functional areas}

\begin{abstract}
The aim of this paper is to do a reflection on the need to modernize the classic concept of the civil servants' corps. The corps, understood as a group of civil servants, has been the most representative element of our model of public employment. However, one new element was brought into the structure of public employment more than sixty years ago: the job position. The job position is the set of duties and tasks assigned to a person. Since then, both institutions must coexist in the Administration, as both are necessary and complementary elements of the structure, not alternative models. Our goal is to update the notion of the civil servants'corps to make it more compatible and consistent with the new dual structure of public employment. The body could be conceived as a correlate of the jobs groups, previously created by the Administration.
\end{abstract}

Keywords: civil servants' corps, jobs positions, jobs groups, functional areas, civil service organizational structure.

Sumario. 1. Planteamiento introductorio. 2. El cuerpo funcionarial como instrumento organizativo, pero, sobre todo, como fenómeno social. Algunas consecuencias. 3. La inserción del puesto de trabajo en la estructura funcionarial y la necesidad de enriquecer la gestión con su contenido técnico. 4. La agrupación de puestos como herramienta que permite la conexión entre las exigencias del puesto y la capacidad del funcionario. 5. Los riesgos de seguir con un modelo corporativo clásico no evolucionado. El ejemplo valenciano: ¿los cuerpos como "nichos profesionales"? 6. Sobre la conveniencia de

* Universidad de Castilla La Mancha

Josefa.Cantero@uclm.es 
avanzar hacia una noción más moderna y técnica del cuerpo funcionarial como correlato de las áreas funcionales. Bibliografía.

Cómo citar: Cantero Martínez, J., «Hacia una concepción más técnica y moderna de los cuerpos de funcionarios: el cuerpo como relato de las áreas funcionales», en Cuadernos de Gobierno y Administración Pública 4-1, 39-57.

\section{Planteamiento introductorio}

El cuerpo funcionarial, entendido como una agrupación de funcionarios basada en la formación y cualificación homogénea que se exige para el cumplimiento de determinadas funciones, ha sido uno de los elementos más característicos e identificativos de nuestra función pública. Los cuerpos de funcionarios expresan el elemento de especialidad profesional que requiere el abigarrado conjunto de la función pública (Sánchez Morón, 2014:149). Se fueron conformando a lo largo del siglo XIX como el elemento más esencial del modelo cerrado y clásico de función pública, como la unidad básica de la estructura funcionarial. El cuerpo, no sólo determinaba el acceso a la función pública, sino que a los funcionarios pertenecientes al cuerpo se les asignaba en exclusiva el ejercicio de las funciones propias del mismo en virtud precisamente de ese componente de especialización que incorpora el cuerpo. Además, el ingreso en el cuerpo determinaba directamente el futuro del funcionario, sus retribuciones e incluso las posibilidades de hacer carrera profesional. Se trataba de una concepción un tanto

Con la Ley de Funcionarios Civiles del Estado de 1964, primero, y después con la Ley 30/1984, de Medidas para la Reforma de la Función Pública, se introdujo una nueva pieza en la estructura funcionarial, el puesto de trabajo. Desde aquel momento la estructura funcionarial ha estado basada en dos instrumentos, uno de carácter subjetivo y referido a las personas: los cuerpos, como agrupación de funcionarios, y otro de naturaleza objetiva y basado en el puesto de trabajo, que se refiere a la forma de organizar las funciones y responsabilidades que tiene atribuida una Administración, a la acotación de las funciones en una organización (Gorriti Bontigui, 2013). A estos efectos, las Administraciones públicas, a pesar de su especial estatus, no dejan de ser organizaciones, entendidas como una estructura formal de relaciones entre puestos de trabajo y personas para poder acometer las responsabilidades asumidas por estos, que surgen de los distintos acotamientos horizontales y verticales de funciones (De la Fuente Sabater, García Tenorio Ronda, Guerras Martín y Hernángomez Barahona, 1997).

La introducción de este nuevo componente de la estructura funcionarial ha sido vista e interpretada con gran recelo por parte de la doctrina, hasta el punto de que se ha intentado explicar como un elemento introducido conscientemente por el legislador para devaluar y desvirtuar el poder de los cuerpos funcionariales. Algunos autores se han referido a este fenómeno como un ejemplo de "contaminación anglosajona" o como un "golpe de gracia al sistema de cuerpos", explicándolo como el fruto de una "notable obsesión anticorporativa de la Ley, una satanización casi de los Cuerpos de funcionarios, como si fueran una clase social a abatir que sistemáticamente se apropia en su beneficio del servicio público cuya gestión tiene encomendada" (Parada Vázquez y Fuentetaja Pastor, 2013: 76, 88, 91 y 92). Tal vez ello 
explique el escaso interés que ha demostrado nuestro legislador durante todos estos años por dotar de contenido técnico al puesto de trabajo y por intentar armonizar adecuadamente ambos instrumentos, tratándolos más bien como si de dos realidades contrapuestas y alternativas se trataran.

La explicación de su implantación desde esta perspectiva estrictamente histórica y sociológica ha motivado la aparición de importantes disfunciones en la estructura que han afectado a la mayor parte de las instituciones funcionariales. Da la impresión, efectivamente, de que nuestros legisladores han querido configurarlos como dos islotes aislados en la estructura o, mejor dicho, no han sabido establecer los adecuados lazos de unión entre ambos elementos para conseguir una coexistencia armónica, lo que ha provocado toda una cascada de desajustes en la gestión de personal que ahora el nuevo estatuto básico funcionarial podría enmendar si se sabe utilizar adecuadamente el abanico de herramientas técnicas y organizativas que menciona. Urge dar también una explicación meramente técnica y concebir la introducción del puesto de trabajo en la Administración también como una necesidad organizativa. Para ello, el primer paso será cubrir la laguna del legislador respecto del puesto de trabajo con las aportaciones técnicas que provienen de otras disciplinas y que nos llevan a distinguir entre personas y puestos, entre funciones y tareas dentro del puesto de trabajo (Gorriti, 2013). Esta distinción será fundamental para después trabar y ligar ambos elementos estructurales, aunque, como a nadie se le escapa, supone limitar los amplios márgenes de libertad que hasta ahora ha tenido la Administración en esta materia al apoyarse directamente en el ejercicio de potestades autoorganizatorias. El segundo paso requiere modernizar y tecnificar la idea del cuerpo de funcionarios por relación al puesto de trabajo y, más concretamente, por relación a las agrupaciones de puestos denominadas "áreas funcionales".

Efectivamente, fue el Estatuto Básico del Empleado Público (EBEP), aprobado por la Ley 7/2007, de 12 de abril, y ahora recogido en el Real Decreto Legislativo $5 / 2015$, de 30 de octubre, por el que se aprueba el Texto Refundido de la Ley del Estatuto Básico del Empleado Público, el que por vez primera se refiere al contenido del puesto de trabajo, a sus funciones y tareas, y el que prevé con carácter de norma básica la posibilidad de agrupar también los puestos de trabajo en función de su polivalencia en lo que se han denominado "áreas funcionales". Subyace en el modelo EBEP una concepción nueva y dinámica del puesto de trabajo que es absolutamente imprescindible para aplicar las distintas instituciones funcionariales, especialmente la evaluación del desempeño y el nuevo modelo de carrera horizontal. Pues bien, a partir de los instrumentos y de las herramientas nuevas que prevé la actual legislación estatutaria, podría avanzarse hacia una concepción técnicamente más moderna y útil del cuerpo de funcionarios, adaptada a la nueva realidad normativa y estructural, que tenga en cuenta el previo diseño organizativo realizado por la Administración y la creación de grupos de puestos de trabajo que se caracterizan por exigir una formación y conocimientos homogéneos. De esta manera, los cuerpos de funcionarios vendrían a ser el correlato lógico de las agrupaciones de puestos previamente identificadas por la Administración, de las llamadas áreas funcionales (Gorriti, 2013).

En fin, dejando al margen el interesante enfoque sociológico de los cuerpos funcionariales, nos proponemos en estas líneas centrar el debate fundamentalmente en el carácter técnico y organizativo que tienen estas instituciones. Consideramos que no se trata de instituciones o modelos antagónicos, sino que ambos elementos, cuerpos 
y puestos, son necesarios, inevitables y complementarios. Son las dos patas en las que ha de apoyarse la estructura de nuestra función pública. A partir de ahí, una correcta gestión de personal exige estructurar los puestos de trabajo en la Administración y estructurar a las personas que los ocupan, esto es, a los funcionarios, y este proceso no puede hacerse de forma desligada de los puestos y de sus agrupaciones. Por ello, no se trata de optar por uno $\mathrm{u}$ otro modelo (de puestos o de cuerpos) sino de hacer ambos compatibles y de utilizarlos de la mejor manera posible en beneficio de una mayor eficacia administrativa y, en suma, del interés público (Cantero, 2016).

Para ello, partimos en este análisis de una idea esencial. Además de la interpretación sociológica que se ha dado a este fenómeno, la introducción del puesto de trabajo en la Administración obedeció también a una necesidad organizativa. Los puestos naces porque es necesario acotar las responsabilidades que una persona es capaz de asumir (Gorriti Bontigui, 2013). A ello se refería expresamente -y ya en su díala exposición de motivos de la Ley de Bases de los Funcionarios Civiles del Estado, Ley 109/1963, de 20 de julio, al señalar la necesidad de modernizar la estructura de la función pública y de "incorporar el progreso que se ha producido en los últimos decenios en la ordenación del factor humano en las empresas de todo género. La ciencia de la Organización ofrece nuevas soluciones a los difíciles problemas de selección, formación, estímulo y adecuación de las personas a sus específicas tareas en el cuadro empresarial. La incorporación de esos criterios al ámbito de la Administración pública, con las necesarias adaptaciones a las peculiares características de ésta, habrá de ser, sin duda, provechosa para remozar el derecho positivo español en materia de funcionarios".

En fin, toda organización, sea pública o privada, necesita ordenar y estructurar sus funciones sus puestos de trabajo y a sus empleados. Difícilmente una Administración puede ser eficaz en el desempeño de las tareas y funciones que tiene normativamente encomendadas si no es capaz de diseñar y ordenar adecuadamente sus puestos de trabajo y de organizar a sus funcionarios. Sin una adecuada estructura que armonice los puestos con los cuerpos de funcionarios se pueden producir importantes disfunciones que acaban comprometiendo y afectando, no sólo a la gestión del personal, sino también a la eficacia y a la eficiencia de la Administración en la consecución de los intereses generales que tiene encomendados. Y, lo que es incluso más grave, se corre el riesgo de que la Administración acabe convirtiéndose en una masa amorfa de funcionarios (Nieto, 1996: 153) o en un panal de cuerpos que actúan como compartimentos estancos, como nichos funcionariales, y que hacen prácticamente ingobernable la gestión de su personal. Buen ejemplo de ello nos proporciona la función pública valenciana, que a pesar de que fue uno de los primeros modelos que desarrollaron el EBEP, está actualmente inmersa en un importante proceso de reforma.

\section{El cuerpo funcionarial como instrumento organizativo, pero, sobre todo, como fenómeno social. Algunas consecuencias}

La función pública no nace en nuestro país como un sistema general, como un régimen juríd.ico uniforme aplicable a los servidores públicos, sino que se va gestando a raíz precisamente de la aparición de los grandes cuerpos funcionariales que se iban creando cada vez que la Administración asumía una nueva función (Parada Vázquez 
y Fuentetaja Pastor, 2013: 78 y ss.). Así, para gestionar las obras públicas se crea el Cuerpo de Ingenieros de Caminos; para la gestión de los tributos se instituye un Cuerpo de funcionarios de Hacienda; para cumplir con las funciones de asesoramiento jurídico y defensa del Estado se creó el Cuerpo de Abogados del Estado, etc. La formación de nuestro sistema funcionarial durante el siglo XIX no obedeció a un esquema previamente pensado, a ninguna lógica racional, sino a un cúmulo de circunstancias histórico-políticas en las que no estuvieron ausentes ciertas dosis de improvisación (Jiménez Asensio, 1989, 79 y 81). El cuerpo de funcionarios se convirtió en el elemento más característico y representativo de nuestro modelo de función pública, desempeñando un importante papel en la gestión de personal. No sólo era un instrumento para el acceso, sino también para ordenar la movilidad, la provisión de puestos de trabajo y la carrera funcionarial.

El corporativismo es, sin embargo, un fenómeno enormemente complejo. Incorporaba una importante carga psicológica, en la medida en que el funcionario, más que considerarse como miembro de la Administración, se consideraba básicamente miembro del Cuerpo en el que ingresaba y en el que iba a desarrollar toda su vida profesional. Esta fuerte identificación entre el funcionario y el Cuerpo estuvo en el origen mismo de la aparición del llamado "espíritu del servicio" y del concepto jurídico denominado "las necesidades del servicio", lo que se traducía en un régimen jurídico que potenciaba especialmente sus deberes y su régimen disciplinario (Parada Vázquez y Fuentetaja Pastor, 2013: 77 y 78). Pero, además de ser un instrumento organizativo y estructural de la función pública, el cuerpo también era un fenómeno social, fruto y resultado directo de nuestra historia, de las circunstancias económicas y políticas de nuestro país. Los cuerpos eran, ante todo, potentes grupos sociales organizados con sus propios intereses particulares, que acabaron convirtiéndose en poderosos grupos de interés y, sobre todo, de presión política. "El número y la configuración de los distintos cuerpos determina los modos de acceso a la función pública y, una vez dentro de ella, el haber ingresado en uno u otro cuerpo es lo que condiciona -mucho más que ninguna otra circunstancia personal u orgánicael prestigio, retribución, cualidades del puesto de trabajo y posibilidades de carrera del funcionario. Y a la vez, la configuración de los cuerpos, la organización interna de cada uno y las relaciones entre ellos, constituyen factores que influyen poderosamente en la estructura, competencia y funcionamiento de los órganos administrativos y en las relaciones de la Administración con el conjunto de la sociedad" (De la Oliva y Gutiérrez Reñón, 1968: 17 y ss.).

Ello explica que a través de las reformas llevadas a cabo en los años sesenta y en los años ochenta se intentaran desactivar algunos de los privilegios que habían ido acumulando los cuerpos funcionariales, fundamentalmente con la introducción del puesto de trabajo y con el establecimiento del principio de adscripción indistinta. Asimismo, se introdujo la prohibición de que, con carácter general, se atribuyeran a los cuerpos funciones correspondientes a los órganos administrativos para evitar su "patrimonialización" por parte de los cuerpos y la prohibición de que los tribunales o comisiones de selección estuvieran formados exclusivamente por funcionarios pertenecientes al mismo cuerpo para el que se selecciona, permitiéndose algunas excepciones. Pues bien, el intento de atajar esta otra faceta sociológica de los cuerpos explica la adopción de algunas medidas importantes que acabaron afectando también a la estructura funcionarial, creando importantes disfunciones al privar al cuerpo de algunas de las funciones básicas que hasta entonces 
había tenido en cuanto a la movilidad, provisión de puestos y carrera profesional de los funcionarios.

Efectivamente, debido a la desnaturalización que se fue paulatinamente produciendo de los cuerpos funcionariales y los abusos que en su nombre se cometieron, fueron gestándose serios prejuicios respecto del modelo corporativo, que concluyeron con prácticamente la pérdida de casi todas las funciones organizativas que hasta ese momento había tenido. Quedó relegado como una institución utilizable sólo para el acceso a la Administración y se le despojó de la función esencial que hasta ese momento había tenido como marco competencial delimitador de las posibilidades de actuación y movilidad del funcionario. En el modelo clásico inicial, y una vez producido el ingreso, el funcionario hacía carrera ocupando los distintos puestos reservados a su cuerpo. Aunque las nuevas funciones lógicamente eran cada vez de mayor responsabilidad, no se perdía en el horizonte la experiencia ni la capacidad funcional que el funcionario había demostrado para su ingreso. El cuerpo proporcionaba siempre esta conexión. En el modelo actual, sin embargo, la carrera vertical (basada en la ocupación de puestos) permite al funcionario moverse por la amplia franja de puestos delimitada por el Grupo de titulación y la escala de niveles atribuidos al mismo, pero no hay garantías -salvo excepciones- de conexión con los conocimientos, competencias y capacidades del Cuerpo al que se ingresó. Ello genera, además, un serio problema de movilidad funcionarial en la Administración.

En ausencia de diseño organizativo, el principio de adscripción indistinta de los puestos de trabajo supuso, pues, privar al Cuerpo de una de sus funciones relevantes en relación, sobre todo, con la carrera administrativa y con la provisión de los puestos. Quedó seriamente diluida su función como marco delimitador de competencias, capacidades y conocimientos comunes. Con ello se producía un claro desaprovechamiento de las destrezas, capacidades y de la experiencia que poseía el funcionario, pues éstas se convertían después en prácticamente irrelevantes a la hora de organizar las carreras, la formación o de proveer los puestos de trabajo. Los márgenes de libertad para la Administración en la convocatoria de sus concursos y para el propio funcionario en la planificación de su carrera eran en este sentido prácticamente ilimitados, pues no tenían que responder a un aspecto esencial de cualquier organización como es la atención y el aprovechamiento de las capacidades y conocimientos de las tareas del puesto.

Esta desconexión entre la experiencia del puesto ocupado y las capacidades y destrezas que exige el adecuado desarrollo de las tareas del nuevo puesto puede tener serias repercusiones en la organización administrativa y afectar de modo directo a la eficacia y eficiencia de la actuación administrativa (STS de 5 de junio de 2009, Sala de lo Contencioso-Administrativo, Sección7a, RJ 2009\6512). La eficacia queda comprometida porque al no existir mecanismos estructurales que permitan garantizar que las funciones del nuevo puesto tienen que ver con las del antiguo puesto, se desaprovecha por completo la experiencia en el puesto. No hay garantías de que el funcionario sepa desempeñar las tareas del nuevo puesto. Ello, como a nadie se le escapa, requiere como mínimo realizar una importante inversión de tiempo y recursos en la formación del funcionario, lo que afecta directamente a la eficacia en la prestación del servicio. Al mismo tiempo, una vez perdida la referencia del cuerpo en la provisión de puestos de trabajo y en la planificación de la carrera del funcionario, desaparecen también los obstáculos organizativos para que la Administración provea sus puestos en atención a factores que no tienen relación directa con 
el contenido del puesto y, en consecuencia, con las destrezas y capacidades que fueron acreditadas en el proceso selectivo, o que se adapten los requisitos de sus convocatorias al perfil del candidato que se pretenda beneficiar. Todos estos comportamientos causan graves problemas a la organización administrativa y defraudan las expectativas de los demás funcionarios. Ante este panorama, no es de extrañar que se haya producido lo que algún autor ha calificado como un "desfallecimiento del interés público como fundamento objetivo de la Función Pública" (Fuentetaja Pastor, 2013: 424 y 426).

\section{La inserción del puesto de trabajo en la estructura funcionarial y la necesidad de enriquecer la gestión con su contenido técnico}

La introducción del puesto de trabajo en el sistema funcionarial, no sólo ha sido interpretada con gran recelo por ser un elemento ajeno a nuestro modelo cerrado de función pública, sino que además no ha sido desarrollada en su integridad. El legislador apenas se ha ocupado de su regulación y lo ha considerado meramente como una manifestación del ejercicio de las potestades autoorganizatorias de la Administración. Ello ha dado lugar a importantes ambigüedades que afectan muy negativamente a las diferentes instituciones funcionariales. Como se ha apuntado desde el ámbito de la Psicología del Trabajo y de las Organizaciones, al no haber técnica, el diseño organizativo de los puestos se puede contaminar. Esta contaminación se producirá cuando éstos se diseñan pensando fundamentalmente en las capacidades y destrezas, sabidas o sospechadas, de las personas que los desempeñan (Gorriti Bontigui, reflexiones personales). El resultado ha sido un modelo parcialmente desconectado del cuerpo que urge poner en conexión para una adecuada y eficaz gestión del personal (Arroyo Yanes, 1999: 55).

Su inserción nos ha abocado, efectivamente, hacia un modelo mixto cuya estructura se basa en la existencia de cuerpos y puestos de trabajo. Ello ha presentado algunas disfunciones, a nuestro juicio, no por tratarse de modelos antagónicos, sino más bien por la falta de regulación y desarrollo del nuevo elemento, del puesto de trabajo. Así al menos lo diagnosticó el Informe de la Comisión de Expertos para el Estudio y Preparación del Estatuto Básico del Empleado Público, publicado por el INAP el 25 de abril de 2005 y dirigido por el profesor Miguel Sánchez Morón. Faltaba una definición precisa de lo que hubiera de entenderse por "puesto de trabajo" $\mathrm{y}$, sobre todo, una clarificación de las reglas para combinar los cuerpos y categorías funcionariales con el puesto de trabajo. En la mayor parte de nuestras Administraciones públicas, esta indefinición se ha traducido en una concepción rudimentaria y pobre del puesto, como un acotamiento estático y repetitivo de tareas realizadas por un empleado público o por un grupo de ellos, que no permite desmenuzarlo y, en consecuencia, extraer las consecuencias jurídicas que de ese desmenuzamiento deberían derivarse para la adecuada gestión de las personas. Como se ha recordado, las consecuencias de esta indefinición son muy importantes. Se traducen fundamentalmente en una completa ausencia de flexibilidad en la gestión, la imposibilidad de gestionar la diferencia y en grandes dificultades para implantar la polivalencia de los puestos. Se traza así una "barrera prácticamente infranqueable" para una administración que, por el contrario, debería estar en permanente proceso de adaptación a las necesidades de la sociedad (Férez Fernández, 2006: 73 y 74). 
Sin embargo, con la entrada en vigor del nuevo modelo EBEP, el puesto de trabajo, definido como el conjunto de tareas, funciones, responsabilidades y finalidades que se asignan a una persona en una Administración Pública, debería convertirse en el "núcleo básico de la estructura del empleo público". Su centralidad en la estructura es ya una realidad incuestionable dado que, en torno a él, y tal como se destacó en el Informe de la Comisión de Expertos, se deberían desarrollar necesariamente la definición de los perfiles de idoneidad de las personas para el ejercicio de las funciones mediante procesos que las satisfacen; la asignación y supervisión de las tareas; la evaluación del desempeño de los empleados; la fijación de las retribuciones complementarias y las modalidades de la carrera profesional, tanto de la vertical como de la nueva carrera horizontal (Informe: 78). Pues bien, anta la falta de definición por parte del legislador resulta imprescindible tener en cuenta el contenido técnico que, desde otros ámbitos del saber, fundamentalmente desde el ámbito de la Psicología del Trabajo y de las Organizaciones, se ha dado a esta institución.

Este contenido técnico lleva forzosamente a la distinción conceptual entre las funciones y tareas del puesto, lo que a su vez permite trazar una separación entre el puesto de trabajo y la persona que lo ocupa, el funcionario. Al puesto se refieren las funciones y al funcionario fundamentalmente las tareas que se desempeñan, definidas como procesos de ejecución de las funciones, que son observables, medibles y evaluables (Gorriti, 2002, 2007 y 2013). Las funciones hacen referencia a las responsabilidades generales. Son los enunciados de una responsabilidad que un puesto de trabajo asume respecto de un ámbito determinado por la atribución normativa de una competencia. Para realizar este desmenuzamiento del contenido de los puestos de trabajo, que resulta fase esencial del diseño organizativo, es imprescindible contar con determinados instrumentos organizativos que son los que nos van a proporcionar información desmenuzada sobre ellos. En este sentido, si seguimos el modelo vasco, resultan de gran utilidad los llamados Análisis de puestos que, aunque son procesos muy laboriosos, permiten a la Administración conocer cuáles son las tareas del puesto y qué se necesita para desempeñarlas. Todas estas informaciones relevantes del puesto que se obtienen de los correspondientes análisis, una vez filtradas y gestionadas, dan lugar a las llamadas "monografías del puesto", que serían el resultado final de este proceso y recogerían toda la información del puesto que es necesaria para poder valorarlo. La monografía es una herramienta complementaria de la Relación de Puestos de Trabajo.

Pues bien, cuando se habla de funciones del puesto se hace referencia al enunciado de una responsabilidad que un puesto de trabajo asume respecto de un ámbito concreto, de tal forma que la función identifica qué se hace o qué se debe de hacer en cada puesto de trabajo (Gorriti Bontigui, 2002). Las tareas del puesto, por el contrario, se refieren a los desempeños concretos. Identifican el proceso utilizado para satisfacer las funciones, las cosas que hace el funcionario para poder cumplir adecuadamente con las funciones del puesto. La tarea es un enunciado de actividad que identifica un proceso mediante el cual se satisface la responsabilidad enunciada por la función, identificando, así, el cómo se hace algo o cómo se debe de hacer. Sólo las tareas del funcionario resultan observables y medibles (Gorriti Bontigui, 2002 y Gorriti y Toña, 2006).

Las funciones vendrían directamente determinadas por las competencias que las normas atribuyen a la Administración en cada momento concreto para la satisfacción del interés general y, dentro de ella, a sus órganos a través de las correspondientes 
normas reglamentarias de estructura interna. A partir de esta atribución normativa de competencias, el experto en diseño organizativo puede hacer la acotación de funciones de los puestos de trabajo. Desde este estricto planteamiento técnico y organizativo, la atribución legal de funciones a los Cuerpos como agrupaciones de funcionarios sería un elemento disonante, una anomalía organizativa. En puridad, las funciones deberían asignarse a los puestos de trabajo (elemento objetivo de la estructura) no a las personas (Cuerpos funcionariales como elemento subjetivo de la estructura). Clarificador resulta, en este sentido, la Exposición de Motivos del Decreto Vasco 78/2005, de 12 de abril, por el que se regulan las relaciones de puestos de trabajo de la Administración General de la Comunidad Autónoma de Euskadi y sus Organismos Autónomos. Según se recoge en este texto normativo, el contenido de esta distinción entre funciones y tareas se concretaría en las siguientes ideas básicas:

1. La función indica lo que se debe hacer; mientras que la tarea señala cómo se debe hacer.

2. La función se refiere a una responsabilidad asumida; mientras que la tarea identifica los procesos necesarios para cumplir con esa responsabilidad.

3. La función constituye la unidad organizativa básica para definir el puesto, mientras que la tarea es la unidad básica para la intervención en materia de recursos humanos, entendida como la adecuación de las personas a los puestos: la gestión de la diferencia.

4. La valoración de las funciones es determinante para asignar el nivel del puesto y el correspondiente complemento de destino, mientras que la valoración de las tareas debe servir de fundamento para asignar el correspondiente complemento específico.

5. Las funciones similares permiten definir puestos homogéneos, mientras que las tareas permiten identificar las singularidades estables o contingentes de los puestos, de tal manera que se convierten en la mejor garantía para una adecuada gestión de la diferencia en esos puestos.

Ahora tendríamos que añadir otra idea esencial a esta clarificadora enumeración que hace la normativa vasca. Las tareas (y no las funciones) es lo que permite realizar la evaluación del desempeño, pues sólo ellas son observables, medibles y evaluables. En fin, esta distinción, que ha cuajado en el TRLEBEP (art. 73.2), aunque no sin cierta confusión, multiplica considerablemente las posibilidades de flexibilidad y dinamismo en la gestión de los recursos humanos, incluso de la selección y de la provisión de puestos. Además de resultar un elemento de gran utilidad para realizar los diseños organizativos adecuados, este desmenuzamiento del puesto resulta forzoso para posibilitar una gestión de la diferencia en la Administración, para diferenciar entre personas y puestos. La distinción resulta absolutamente necesaria para la aplicación de los complementos retributivos de carácter objetivo, esto es, los vinculados al puesto de trabajo y sus características, así como para realizar la evaluación del desempeño.

En todo caso, la incorporación del puesto de trabajo a la estructura funcionarial supone reconocer formal y legalmente la distinción entre el elemento subjetivo (el funcionario) y el objetivo (el puesto de trabajo). Se trata de dos caras de la misma moneda, si se permite la expresión. Implica, además, la necesidad de introducir en este ámbito la técnica, el diseño organizativo para estructurar y ordenar, primero los 
puestos y después las personas (Gorriti, 2013). Los importantes avances organizativos que se han producido en los últimos años en el diseño de puestos exigirían reconocer que debe haber una secuencia temporal lógica entre el elemento objetivo y el subjetivo, lo que supondría un importante cambio en nuestro modelo clásico funcionarial y en la forma de hacer las cosas. En buena técnica organizativa, primero habría que diseñar los puestos en la Administración, decidir qué hay que hacer, qué funciones tiene encomendadas normativamente la Administración y cómo organizarlas. Una vez diseñados los puestos mediante la acotación vertical y horizontal de funciones, deberían analizarse y obtenerse sus tareas y sus determinantes de perfil para poder agrupar puestos en función de su polivalencia y ordenarlos a través de las relaciones de puestos de trabajo. Solo después, y en buena técnica organizativa, debería actuarse sobre las personas, sobre los cuerpos de funcionarios, concebidos como correlatos de aquellas agrupaciones. En rigor, y desde un estricto punto de vista técnico, solamente después de haber realizado una reflexión organizativa previa sobre las funciones que debe realizar la Administración puede pensarse en los conocimientos, competencias y capacidades que han de reunir los funcionarios responsables de ejecutarlas.

\section{La agrupación de puestos como herramienta que permite la conexión entre las exigencias del puesto y la capacidad del funcionario}

Especial atención merecen las agrupaciones de puestos mencionadas expresamente en el art. 73.3 del TRLEBEP. Dicho precepto posibilita que la Administración pueda agrupar sus puestos de trabajo en función de sus características para ordenar el acceso, la formación y la movilidad. Esta herramienta permite agrupar puestos de trabajo que son polivalentes, esto es, que requieren conocimientos y destrezas comunes.

La agrupación de puestos se traduce en la creación de un "área funcional" o un "área de especialización", que se lleva siempre a cabo de acuerdo con la mayor o menor polivalencia que muestran dichos puestos de trabajo. Se trata de identificar a través de la Relación de Puestos de Trabajo todos los puestos que desempeñan funciones y tareas que exigen conocimientos y destrezas comunes para crear un grupo. Una vez identificados los puestos agrupables se pueden ordenar con sensatez y criterio técnico los procesos de movilidad - entendida en sentido amplio- y de formación de los funcionarios. Estas nuevas herramientas, no sólo deben reconducir la movilidad del funcionario hacia puestos polivalentes que guarden cierta similitud con el puesto de origen, sino que también permiten identificar los conocimientos, capacidades y competencias requeridas o convenientes para desempeñarlos y a identificar las distancias entre ellos. Contribuyen de modo significativo a acotar y racionalizar la movilidad de los funcionarios en sentido amplio, esto es, la provisión de puestos, la carrera funcionarial e incluso la formación, señalando itinerarios formativos e itinerarios de carrera para el funcionario. Con ello se consigue que los periodos para que los funcionarios sean eficientes en un puesto nuevo se acortan debido a que tienen un bagaje de conocimientos y destrezas afines que les permite adquirir los nuevos conocimientos y destrezas de manera mucho más rápida (López Basterra, 2012: 31, 32 y 40).

En otro tiempo, el aprovechamiento de destrezas y de la experiencia del funcionario venía garantizado directamente por los cuerpos funcionariales. El cuerpo per- 
mitía asegurar que cuando el funcionario cambiaba de puesto, el nuevo destino iba a estar funcionalmente conectado con el puesto ocupado, aunque iba a permitir una mayor responsabilidad y una mayor retribución. El cuerpo permitía aglutinar jerárquicamente a un colectivo de funcionarios dotados de una formación específica para gestionar una función, un servicio público o una determinada rama de la actividad administrativa. El funcionario accedía al cuerpo y dentro de él desarrollaba toda su carrera y su vida profesional, ocupando de forma progresiva y sucesiva los puestos de trabajo que ese cuerpo tenía reservado (Parada Vázquez y Fuentetaja Pástor, 2013: 77). El proceso de desnaturalización del cuerpo que se llevó a cabo desde mediados del siglo pasado y el principio de adscripción indistinta, sin embargo, dieron al traste con esta importante función del Cuerpo, que prácticamente desapareció.

En este sentido, las áreas funcionales permiten fundamentalmente atenuar los problemas de excesiva movilidad que ha creado el principio de adscripción indistinta en nuestro ordenamiento funcionarial. No es inusual que las ventajas obtenidas por la selección del funcionario por cuerpos (o por especialidades de examen u opciones) se pierden después con un modelo de carrera y provisión de puestos de trabajo que permiten amplios márgenes de movilidad y en el que la institución protagonista ya no es normalmente el cuerpo, sino el grupo de titulación. Con ello, la profesionalización y especialización del funcionario que se consigue con este sistema sólo queda garantizado en el momento inicial de selección, en el acceso a la Administración. Después se puede perder casi por completo, con los problemas que ello puede suponer para la organización.

Para evitar esta pérdida podría pensarse en la utilización de algunas de las herramientas que ahora posibilita el Estatuto Básico. Así podría suceder con una recuperación matizada del principio de adscripción de puestos a los cuerpos cuando ello se derive de la naturaleza de las funciones, con el establecimiento de agrupaciones de puestos de trabajo, con el establecimiento de itinerarios formativos y de carrera o, incluso, como se ha hecho en algunos modelos autonómicos (Valencia, Extremadura, Galicia o Castilla-La Mancha), recurriendo a otros instrumentos organizativos bastante más insólitos como los llamados "itinerarios profesionales", aunque esta vez de naturaleza corporativa. Con estos instrumentos se actúa sobre el elemento subjetivo de la estructura, esto es, sobre los cuerpos funcionariales. Con ellos se hace referencia a los cuerpos, escalas o, en su caso, especialidades en los distintos grupos y subgrupos de clasificación profesional, que tengan asignadas una o varias áreas de competencias, capacidades, conocimientos y formación comunes. Estos instrumentos se han establecido en las distintas legislaciones autonómicas de desarrollo del EBEP como un intento de ordenar y racionalizar en cierta medida la promoción interna vertical en la Administración.

En fin, la técnica de la agrupación de puestos vendría a solucionar estos problemas de dispersión, aunque, eso sí, actuando esta vez, no en las personas (en los cuerpos o elemento subjetivo de la estructura) sino en los puestos de trabajo (elemento estructural objetivo). Como herramienta resulta de gran utilidad para la gestión de los recursos humanos, toda vez que es el mecanismo concebido por el legislador para enmendar la excesiva dispersión del funcionario y garantizar en la Administración el principio de especialización e idoneidad funcionarial. En este sentido, vendría a cumplir funciones de acotación parecidas a las que en otro tiempo desempeñó el cuerpo y a demostrar que algunos aspectos relacionados con el elemento objetivo de la estructura, con el puesto de trabajo, se plantean como soluciones a algu- 
nos de los problemas que se han generado en los últimos años como consecuencia de medidas que han sido adoptadas sobre el elemento subjetivo, en este caso, con la clara intencionalidad de disminuir el poder que tenían los cuerpos y la patrimonialización de las funciones administrativas que había generado el sistema corporativo. Ello evidencia que, en realidad, existe una clara relación de complementariedad entre ambos elementos más que de antagonismo.

La nueva concepción de cuerpo que proponemos en este trabajo, siguiendo las ideas originales apuntadas en diversos trabajos de Gorriti Bontigui y en conversaciones con el autor, se basa en la consideración de que el cuerpo debe ser la proyección en las personas de las polivalencias nacidas de las áreas funcionales. Sólo por el hecho de existir polivalencias que agrupan puestos tiene sentido agrupar personas, a los funcionarios públicos.

Ya el informe elaborado por la Comisión de Expertos había criticado la excesiva rigidez del modelo existente y recomendaba que cada Administración, atendiendo a sus propias necesidades organizativas, diseñara sus puestos de trabajo, los ordenara, los clasificara y los agrupara para poder identificar la estructura global de la organización del trabajo, la jerarquización de las tareas y, sobre todo, pudiera reorientar la excesiva movilidad de los funcionarios en atención básicamente a las necesidades de la Administración. El éxito está en lograr un equilibrio entre las necesidades organizativas y las expectativas de carrera del funcionario. La identificación de grupos de puestos polivalentes, las llamadas áreas funcionarias, es el instrumento organizativo que posibilita este equilibrio.

En este sentido, el área funcional o agrupación de puestos tiene una doble naturaleza jurídica. Consiste, en primer lugar -y, ante todo-, en una potestad organizatoria que responde a un criterio estrictamente técnico. La creación de estas agrupaciones y la decisión de adscribir un puesto a una determinada área funcional es, efectivamente, una decisión rigurosamente organizativa, que corresponde tomar a la propia Administración pública y que ha de estar basada exclusivamente en la aplicación de criterios técnicos, en la identificación de los puestos polivalentes. Ello supone reconocer amplios márgenes de libertad a la Administración, tal como es propio del ejercicio de la potestad autoorganizatoria, y permitir la intervención en esta materia, tanto de normas reglamentarias como de otros instrumentos internos organizativos y de gestión.

Ahora bien, además de esta naturaleza estrictamente técnica, las agrupaciones de puestos pueden tener un importante efecto condicionante y delimitador del ejercicio de los derechos del funcionario. En la medida en que pueden afectar a sus derechos formativos y que siempre van a tener consecuencias directas en la carrera vertical del funcionario, en su movilidad a través de la provisión de puestos de trabajo, debe ser el legislador el que intervenga con carácter previo creando y reconociendo estos instrumentos $\mathrm{y}$, sobre todo, delimitando el valor que tienen y sus efectos en los derechos funcionariales y, en general, en la gestión de los recursos humanos (STS de 5 de junio de 2009, Sala de lo Contencioso-Administrativo, Sección7 ${ }^{\mathrm{a}}$, RJ 2009\6512).

La utilización de estos instrumentos posibilita a los funcionarios la autogestión de sus carreras, orientándolos hacia puestos de trabajo que son coherentes con la experiencia previa que posean, de tal forma que los conocimientos y destrezas nuevos que adquieran estén siempre en consonancia con los antiguos y creen sinergias en la mejora del desempeño y de su propia satisfacción (Longo Martínez, 2004). En este sentido, esta institución es también plenamente coherente con uno de los prin- 
cipios básicos del régimen funcionarial que debe orientar, no sólo las decisiones del legislador, sino también -y de modo directo- las de la Administración en la toma de decisiones organizativas. Nos referimos al "principio básico de la utilización racional del funcionariado existente" proclamado por nuestro Tribunal Constitucional y que obliga a la Administración a actuar de la manera necesaria para garantizar la efectividad de dicho principio (STC 99/2016, de 25 de mayo, STC 76/1983, de 5 de agosto, y STC8/2010, de 27 de abril).

Además, las áreas funcionales suelen complementarse con otras herramientas organizativas de ordenación funcionarial que resultan también de gran utilidad y que permiten extender los ámbitos de movilidad y carrea del funcionario dentro de su Administración. Así sucede, por ejemplo, con las llamadas áreas relacionales o también llamadas subáreas de especialización en algunas Comunidades Autónomas (art. 22.2 de la Ley 4/2011, de 10 de marzo, de Empleo Público de Castilla-La Mancha). El área relacional de un puesto de trabajo concreto se crea como un área funcional distinta del área al que está adscrito dicho puesto y con la que se relaciona en función de los cometidos, características y procedimientos de trabajo análogos que desarrolla. Estos otros instrumentos permiten también ampliar ordenada y racionalmente el ámbito de la movilidad del funcionario sin perder nunca el elemento común de los conocimientos, aunque en estos casos existe una relación más débil y, por tanto, de mayor peaje formativo para la movilidad entre ellas. Por ello, mientras que el puesto de trabajo está adscrito a una única área funcional, pueden tener una o varias áreas relacionales.

En fin, una utilización combinada de estos elementos permitiría exprimir al máximo las destrezas, las capacidades y la propia experiencia de los funcionarios para la provisión de puestos, la carrera o incluso la formación mediante el establecimiento de los correspondientes itinerarios formativos y de carrera, toda vez que disminuyen considerablemente los períodos destinados al aprendizaje del funcionario en el desempeño de las tareas del nuevo puesto. Se trataría de realizar, sin más, una lectura desde las necesidades de la organización administrativa para lograr un aprovechamiento óptimo de la experiencia del personal.

A partir de este esquema, el cuerpo debería concebirse técnicamente como una evolución del concepto clásico que hemos heredado. Se trataría de revalorizarlo y no de considerarlo como una mera solución histórica de compromiso que hemos heredado y que hay que mantener a toda costa porque es el elemento más característico de nuestro modelo de clásico de función pública. Especialmente en las estructuras administrativas más complejas y extensas, el cuerpo de funcionarios debería concebirse como un correlato lógico y secuencial del diseño organizativo, de las agrupaciones de puestos realizadas en virtud de la polivalencia de los puestos y de las destrezas y conocimientos que estos exigen.

\section{Los riesgos de seguir con el modelo corporativo clásico. El ejemplo valenciano: ¿los cuerpos como "nichos profesionales"?}

Paradigmático es el ejemplo de la función pública valenciana. La Ley 10/2010, de 9 de julio, de la Generalitat, de Ordenación y Gestión de la Función Pública Valenciana, fue una de las primeras normas que vinieron a desarrollar el nuevo modelo que estableció el EBEP en el año 2007. Optó decididamente por un modelo corpo- 
rativo clásico frente al modelo de puestos de trabajo, presentando dicha opción como una de las principales novedades de la ley. Estructura al personal a su servicio en cuerpos, escalas y agrupaciones funcionariales. Ello, como explica la propia exposición de motivos de la ley, implica un auténtico cambio en la función pública valenciana. Significa "el paso de una administración de puestos de trabajo a una administración organizada por funciones y por las competencias, conocimientos y capacidades comunes que los empleados deben reunir para su desempeño, lo que, sin duda alguna, contribuye a dotar de mayor profesionalidad y especialización a la función pública valenciana". Sin embargo, han pasado tan sólo seis años y el modelo está en discusión debido a los grandes problemas que ha presentado.

El modelo valenciano optó claramente por el sistema corporativo clásico como alternativa al modelo de puestos de trabajo, como si de dos realidades distintas y antagónicas se tratara. Resultado de ello fue la aparición de una estructura hipercorporativa compuesta por más de 350 cuerpos funcionariales. Se crearon varios centenares de cuerpos y escalas de diverso nivel y denominación (más de 200 cuerpos de Administración General y 155 en la Administración especial) y además se les distribuyeron entre ellos las funciones administrativas, de manera que da la impresión de atribuir la "titularidad" de las funciones a los cuerpos y escalas. A pesar de esta proliferación de cuerpos, los datos demuestran que más del 83 por 100 de los efectivos de la Administración General de la Generalitat se integran en tan solo 13 cuerpos y escalas y que, asimismo, existen algunos cuerpos formados por un solo funcionario y otros conformados por tan solo algún funcionario más.

Este modelo está inmerso en un importante proceso de reforma y ha sido muy duramente criticado por el reciente Informe para la modificación de la Ley 10/2010, de 9 de julio, de la Generalitat, de Ordenación y Gestión de la Función Pública Valenciana, elaborado por la Comisión creada por Resolución de la Conselleria de Justicia, Administración Pública, Reformas Democráticas y Libertades Públicas de la Generalitat de 3 de marzo de 2016. Ha generado una enorme rigidez en la provisión de los puestos de trabajo, dificulta de manera radical la movilidad interna y crea la imagen de que se han "patrimonializado" por completo las funciones públicas por parte de los cuerpos de la Generalitat.

Efectivamente, a través de los cuatro Anexos que contiene la Ley se asignan en exclusiva a cada cuerpo y escala determinadas funciones. Ello provoca importantes problemas teóricos y prácticos. Desde una perspectiva estrictamente teórica, y tal como resalta el Informe, da la impresión de que las funciones administrativas, en vez de ser un elemento de ordenación del trabajo a disposición de la Administración, son más bien una especie de "patrimonio" de cada uno de los cuerpos o escalas. Asimismo, esta concepción teórica también tiene importantes consecuencias prácticas que perturban por completo la gestión, haciéndola considerablemente menos eficaz, toda vez que introducen un elemento de extraordinaria rigidez. Al menos de una forma implícita parece que se está tolerando que los funcionarios de cada cuerpo y escala "se acantonen en los puestos en que se ejercen sus propias funciones y eventualmente se consideren legitimados para rechazar cualquier otra". De esta manera, la patrimonialización de las funciones repercute directamente en los procedimientos de provisión de puestos, limitando considerablemente su alcance y dificultando de forma notable otros supuestos de movilidad por necesidades del servicio. "La organización queda petrificada en un modelo rígido que dificulta el traslado de los efectivos a dónde son necesarios y puede dejar ociosos indefinidamente a los integran- 
tes de cuerpos y escalas con funciones que dejan de ser necesarias o relevantes para la Administración. Ello por no hablar de la enorme diversificación de procedimientos de acceso que conlleva, en detrimento de la eficacia y la agilidad que debe reunir el proceso de selección en su conjunto".

A mayor abundamiento, se ha detectado otro importante problema añadido: la práctica incomunicación ente los diferentes sectores del empleo público de la Generalitat, entre sus servicios generales, la sanidad, la educación y la justicia. Los funcionarios de cada uno de estos sectores se han organizado en cuerpos distintos, que son además gestionados de modo prácticamente independiente por las diferentes Consellerias, y ello a pesar de que, en muchos casos, sus funciones son absolutamente idénticas e intercambiables. Esta circunstancia provoca un importantísimo problema de gestión, toda vez que esta tajante separación impide aprovechar los efectivos, al tiempo que limita las oportunidades de carrera vertical de muchos empleados, hasta el punto de que parece "como si se hubiera efectuado una perfecta disección corporativa, pensada más en los nichos profesionales o gremiales del funcionariado que en el interés del servicio público" (Informe, 2016: 31 y 90). No es de extrañar, dirá el informe, que esa rígida estructura corporativa, que más bien parece un residuo de épocas ya lejanas en la Administración española, no haya tenido hasta ahora verdaderas consecuencias prácticas en el plano de los procedimientos de acceso y provisión, así como que se haya creado una "articulación" informal y paralela de la organización funcional del trabajo. El análisis ha llevado incluso a los autores del informe a considerar que el modelo corporativo valenciano es "un modelo inservible, sustituido por una red de relaciones personales poco objetiva y transparente" (Informe, 2016: 91 y 92).

En fin, el modelo valenciano nos alecciona a la perfección de los riesgos que plantea el modelo corporativo clásico con todos sus vicios: atribución directa y en exclusiva de funciones al cuerpo, compartimentalización de la función pública hasta crear auténticos "nichos funcionariales" que dificultan notablemente la gestión del personal y la idea errónea de que el legislador debe optar forzosamente por un único elemento estructural, el cuerpo o el puesto, relegando prácticamente al otro al ostracismo. Así se sugiere en la exposición de motivos de la ley. Por el contrario, tal como en este trabajo mantenemos, ambos elementos son inevitables, necesarios y complementarios. Sin embargo, deben de utilizarse de forma diferente. Los cuerpos deben concebirse de una forma mucho más amplia y tendiendo a estructuras mucho más planas y sencillas que posibiliten gestionar razonablemente el acceso, la movilidad e incluso una eventual atribución temporal de funciones. Así de tajante se manifiesta también el Informe al concluir que, en función del previo análisis realizado y de las graves disfunciones detectadas en el modelo corporativo, se propone el mantenimiento de los cuerpos y algunas escalas "como estructura de selección basadas en las especialidades profesionales, pero combinándola con la más amplia polivalencia de los efectivos y movilidad funcional que sea compatible con sus competencias".

\section{Sobre la conveniencia de avanzar hacia una noción más moderna y técnica del cuerpo como correlato de las áreas funcionales}

El modelo valenciano nos ilustra de los riesgos que supone dar un paso atrás en esta materia para volver a la concepción más clásica y rancia del cuerpo funcionarial. No 
queda otro remedio que seguir hacia delante y tratar de modernizar esta institución adaptándola a la nueva estructura dual y a las nuevas herramientas organizativas que posibilita el modelo EBEP, especialmente a las agrupaciones de puestos.

La polivalencia hace referencia al grado de similitud que diferentes puestos de trabajo tienen en cuanto a los conocimientos y destrezas exigidos para la eficaz ejecución de las tareas que son más representativas en dichos puestos (Férez Fernández, 2006:79). En este sentido, la agrupación funcional o polivalente de puestos nos permite también conocer los perfiles de los funcionarios que deben ocuparlos $\mathrm{y}$, sobre todo, aprovechar su experiencia para lograr un rendimiento óptimo. Ahora se trataría de dar un paso más y permitir que estos avances técnicos y organizativos que suponen las agrupaciones de puestos lleguen también a las agrupaciones de personas, a los Cuerpos. Esta nueva concepción supondría un importante cambio respecto de la noción clásica del Cuerpo y su papel en la estructura funcionarial.

Desde un estricto punto de vista organizativo, esta identificación de áreas funcionales debería dar al legislador las pistas para la creación de los cuerpos funcionariales. Como expresa la doctrina más especializada en esta materia, todo este cambio conceptual se encerraría en la siguiente máxima: si no sabemos previamente qué hay que hacer en la Administración, ¿cómo podemos saber quién puede hacerlo? En este sentido, dirá Gorriti Bontigui, que, "si hay diseño organizativo los cuerpos deberían pasar a un segundo plano o, por lo menos, ser posteriores y coherentes con las previas decisiones que se hayan tomado respecto a la forma de organizarlos porque las personas (los funcionarios públicos, que es lo que agrupan los cuerpos) sólo son necesarias en función de lo que tienen que hacer, no en función de la titulación que tienen que sólo es condición para hacer" (Gorriti, 2002 y 2013). Dirá por ello este autor que los cuerpos deben evolucionar hacia un nuevo contenido. "Como tal agrupación de funcionarios deben establecerse una vez que se han delimitado los diseños organizativos necesarios para cumplir el servicio público; deben ser el correlato lógico y posterior de decisiones organizativas y del estudio de aptitudes, conocimientos y destrezas necesarias para poder cumplir con los comportamientos laborales relevantes que satisfacen las responsabilidades asumidas por el servicio público. Sin haber organizado lo que hay que hacer, cómo debe hacerse y qué se debe saber y tener para poder hacerlo, no pueden decidirse los cuerpos" (Gorriti, 2011:152).

En todo caso, en este trabajo partimos de una idea esencial: la enorme importancia y el papel decisivo que deberían tener estas agrupaciones en la definición misma de los cuerpos funcionariales. La incorporación de la técnica al diseño organizativo debería permitirnos avanzar hacia una noción más amplia, moderna y técnica del cuerpo que lo identifique como un correlato de las áreas funcionales, como su consecuencia lógica. Las ventajas que esta nueva concepción aportaría son muchas. En primer lugar, ello permitiría recuperar también el protagonismo que en otro tiempo lejano tuvo el Cuerpo de funcionarios en la Función Pública, legitimarlo desde la eficacia de la actuación administrativa y, sobre todo, darle una utilidad mayor que la que tiene en la actualidad. En segundo lugar, permitiría recuperar nuevamente en importante papel que en sus orígenes tuvo para acotar la movilidad funcionarial y la carrera vertical en la Administración (Cantero Martínez, 2016). En tercer lugar, el nuevo concepto reformado y avanzado del cuerpo consentiría estructuras mucho más planas y sencillas, acordes también con la nueva concepción generalista de las titulaciones que se deriva de las últimas reformas educativas. Evitaría la rigidez y las disfunciones que provoca el encasillamiento de los funcionarios en cuerpos iden- 
tificados excesivamente con determinadas titulaciones cuando ello no sea absolutamente necesario.

Por último, aunque no por ello menos importante, permitiría conectar los dos elementos de la estructura funcionarial, el cuerpo con el puesto de trabajo. Las agrupaciones de puestos en las Relaciones de puestos de Trabajo, en este sentido, vendrían a desarrollar un papel esencial para establecer la conexión perdida entre el elemento objetivo de la estructura y el elemento subjetivo, permitiendo un juego armónico entre ambos que, sin duda, mejoraría considerablemente la gestión y contribuiría a aumentar la eficacia de la actuación administrativa.

Si dejamos al margen el fuerte componente sociológico del cuerpo y hacemos una lectura eminentemente técnica de esta institución, son muchas las disfunciones que, a día de hoy, presenta. Ha perdido algunas de las importantes funciones que en sus orígenes tenía, fundamentalmente en lo relativo a la acotación y ordenación de las carreras funcionariales. Asimismo, los avances técnicos que se han producido en materia de diseño organizativo permiten incluso poner en evidencia el modo en que se crean los cuerpos, atribuyéndoles directamente las funciones que, en no pocas ocasiones, coinciden con las asignadas a los órganos, creando el indeseable efecto de la apropiación o "patrimonialización" de las funciones por los cuerpos. Fundamentalmente desde el punto de vista de la Psicología del Trabajo y de las Organizaciones, las funciones deberían predicarse de los puestos, más que de los cuerpos, pues éstas, junto con las tareas, conforman el contenido de los puestos de trabajo, tal como antes se ha explicado. Ello no significa que esta institución haya perdido su razón de ser. Todo lo contrario. En toda organización compleja hay que estructurar los puestos y agrupar a las personas que los ocupan. Simplemente entendemos que el concepto de Cuerpo debería modernizarse y evolucionar en coherencia con la nueva estructura dual de la función pública, con los nuevos instrumentos de organización que diseña el legislador básico estatutario y con los importantes avances técnicos que se han producido en materia organizativa.

Esta adaptación es necesaria especialmente en las Administraciones más grandes y voluminosas en cuanto al número de empleados, pues especialmente en estas estructuras complejas resulta de gran utilidad recurrir a las agrupaciones de puestos para ordenar sensatamente los procesos de movilidad de los funcionarios (carrera vertical y provisión de puestos de trabajo, fundamentalmente). Se trataría, en suma, de ajustar y acomodar esta institución al actual modelo y a los nuevos avances técnicos que posibilita la nueva concepción del puesto de trabajo y las nuevas herramientas que permite el TRLEBEP. Este ajuste pasaría por incorporar al cuerpo un fuerte contenido técnico del que ahora prácticamente carece para hacerlo coincidir con las exigencias de capacidad del funcionario que se derivan de las áreas funcionales. Si no se hace así, corremos el riesgo de que el cuerpo se convierta en un elemento desconectado por completo de los puestos, extemporáneo, anacrónico y de escasa utilidad en la estructura funcionarial.

Efectivamente, si las agrupaciones de puestos permiten identificar aquellos que requieren competencias, capacidades y conocimientos comunes, las agrupaciones de funcionarios (los cuerpos) no deberían diferir mucho de aquéllas, sino más bien ser su consecuencia lógica, su correlato. Ello supone un punto de inflexión en la concepción clásica de los cuerpos, que se han creado directamente por el legislador a raíz de las funciones nuevas que iba asumiendo la Administración y sin ninguna intervención previa de diseño organizativo. 
Esta nueva visión permitiría conectar y armonizar a la perfección los dos elementos de la estructura funcionarial en una lógica relación de complementariedad y no de antagonismo de modelos, evitando así muchas de las disfunciones que se han producido en estos años. Ello, sin duda, revertiría en una actuación más eficaz de nuestras Administraciones públicas pues, como se ha dicho, la clave de la eficacia de la Administración radica fundamentalmente en la calidad de quienes la sirven y para ello es imprescindible contar con una sólida estructura funcionarial.

Esta configuración de los cuerpos funcionariales como un correlato técnico de las agrupaciones de puestos de trabajo, de las áreas funcionales, implicaría un cambio importante en la cultura de la Administración y en la forma y secuencia temporal de hacer las cosas. La incorporación del criterio técnico supondría limitar considerablemente el ámbito de discrecionalidad del que disfruta ahora la Administración para hacer su clasificación de puestos y diseños organizativos. Implica, asimismo, dejar el protagonismo inicial a la técnica para hacer el diseño organizativo de los puestos de trabajo y agruparlos en áreas funcionales tras analizar los puestos y, solo después, debería el legislador sancionar esa solución organizativa creando los correspondientes cuerpos en armonía con aquéllas.

En fin, esta concepción avanzada del cuerpo permitiría legitimar estructuras más planas y sencillas en la Administración y poner en conexión ambos elementos estructurales. Es imprescindible, pues, que ambos instrumentos se utilicen y relacionen de una forma óptima porque así lo exige la organización y las necesidades del servicio. Sin una adecuada estructuración de la función pública se pueden producir importantes disfunciones que acaban comprometiendo la eficacia y a la eficiencia de la Administración en la consecución de los intereses generales que tiene encomendados. No hemos de olvidar que la clave de la eficacia de la Administración radica fundamentalmente en la calidad de quienes la sirven y en el acertado régimen de personal que tenga establecido.

\section{Bibliografía}

Arroyo Yánez, L.M. (1999). "La ordenación jurídica de la carrera administrativa ante su reforma", El Estatuto de la Función Pública, ¿La reforma adecuada? Fundación Genesián, Sevilla.

Cantero Martínez, J. (2016). Claves para la modernización de la estructura funcionarial. La coexistencia ordenada de cuerpos y puestos de trabajo. Thomson Reuters-Aranzadi, Madrid.

De la Fuente Sabater, J.M., García Tenorio Ronda, J., Guerras Martín, L.A. y Hernángomez Barahona, J. (1997). Diseño organizativo de la empresa. Civitas, Madrid.

De la Oliva, A. y Gutiérrez Reñón, A. (1968). "Los cuerpos de funcionarios", en Documentación Administrativa, n. 124, pp. 11-70.

Férez Fernández, M. (2006). La carrera administrativa: nuevas perspectivas. Colección Estudios de Relaciones Laborales, Barcelona.

Fuentetaja Pastor, J. A. (2013). Pasado, presente y futuro de la Función Pública. Thomson Reuters-Civitas, Navarra.

Gorriti Bontigui, M (2011). "El sistema de selección para el acceso a una Función Pública postburocrática”, en Nuevas Políticas Públicas. Anuario Multidisciplinar para la Modernización de las Administraciones Públicas, n. 7, pp. 147-161. 
Gorriti Bontigui, M. (2007). "El diseño de funciones y puestos en la administración”, en Nuevas Políticas Públicas. Anuario multidisciplinar para la modernización de las Administraciones Públicas, n. 3, pp. 201-233.

Gorriti Bontigui, M. (2013). "Un sistema de reforma del empleo público alternativo a los recortes de personal", en Revista Vasca de Gestión de Personas y Organización, n. 4, pp. 2-33.

Gorriti Bontigui, M. (2002). "Análisis funcional de los grupos A y B de la Administración General del País Vasco", en Revista Vasca de Administración Pública, n. 63, pp. 205-242.

Gorriti Bontigui, M. y López Basterra, J. (2009). Identificación de criterios de desempeño a partir del análisis del puesto. IVAP, Oñati.

- Gorriti Bontigui, M. y Toña F. (2006). "El nuevo modelo de organización y recursos humanos de la Administración General de la Comunidad Autónoma del País Vasco", en Presupuesto y Gasto Público, no 41.

Jiménez Asensio, R (2010). "Cuerpos generales versus cuerpos especiales: La fragmentación de la función pública española en el siglo XIX", en Revista Vasca de Administración Pública, n. 23, pp. 81-110.

Longo Martínez, F. (2004). Mérito y flexibilidad: La gestión de las personas en las organizaciones del sector público. Paidós, Barcelona.

López Basterra, J. (2012). "Carrera administrativa: Identificación de las áreas funcionales", en la Revista Vasca de Gestión de Personas y Organizaciones Públicas, n. 3, pp. 30-43.

Nieto, A. (1996). La "nueva" organización del desgobierno. Editorial Ariel, Madrid.

Parada Vázquez, R. y Fuentetaja Pastor, J. A. (2013). Derecho de la función públi$c a$. OPEN Ediciones Universitarias, Madrid.

Sánchez Morón, M. (2016). Derecho de la función pública. Tecnos, Madrid. 
